J. Lake Sci. (湖泊科学), 2013, 25(1):9-15

http: //www. jlakes. org. E-mail : jlakes@niglas.ac.cn

(C) 2013 by Journal of Lake Sciences

\title{
改性当地土壤技术修复富营养化水体综合效果研究：II．底栖动物群 落结构和多样性的响应
}

\author{
尚媛媛 ${ }^{1}$, 潘 纲 ${ }^{1 * *}$, 代立春 ${ }^{1}$, 李 梁 $^{1}$, 李 宏 $^{1}$, 毕 䂞 $^{1}$, 王 丹 $^{1}$, 李巧霞 ${ }^{1}$, 龚志军 ${ }^{2}$ \\ (1:中国科学院生态环境研究中心环境水质学国家重点实验室,北京 100085) \\ (2:中国科学院南京地理与湖泊研究所,南京 210008)
}

摘 要: 从 2010 年 10 月开始在太湖梅梁湾围隔内实验区实施了改性当地土壤技术,在研究其对水体富营养化和蓝藻水 华长效控制作用的同时,重点研究了底栖动物群落对此技术的响应. 研究发现: 经过 11 个月的处理,相比对照区, 实验区 内软体动物的平均密度和生物量分别增长了 $124 \%$ 和 $33.8 \%$, 底栖动物 Margalef 和 Shannon-Wiener 多样性指数分别增长 了 $41.1 \%$ 和 $18.5 \%$. 环境因子和底栖动物群落的典范对应分析发现叶绿素 $\mathrm{a} 、$ 温度、溶解氧和总磷对底栖动物群落有显著 影响. 本研究表明通过改性当地土壤技术降低水体营养盐含量和叶绿素 $\mathrm{a}$ 含量、增加底泥表层溶解氧含量,可以在一定程 度上改善底栖动物生境, 提高其物种多样性.

关键词: 改性当地土壤;富营养化; 底栖动物;群落结构;物种多样性;太湖;梅梁湾

\section{Eutrophication control in eutrophic water using modified local soil technology: II . Re- sponse of zoobenthos community structure and diversity}

SHANG Yuanyuan ${ }^{1}$, PAN Gang ${ }^{1}$, DAI Lichun ${ }^{1}$, LI Liang ${ }^{1}$, LI Hong ${ }^{1}$, BI Lei ${ }^{1}$, WANG Dan $^{1}$, LI Qiaoxia ${ }^{1}$ \& GONG Zhijun ${ }^{2}$

(1: State Key Laboratory of Environmental Aquatic Chemistry, Research Center for Eco-environmental Sciences, Chinese Academy of Sciences, Beijing 100085 , P. R. China)

(2: Nanjing Institute of Geography and Limnology, Chinese Academy of Sciences, Nanjing 210008, P. R. China)

Abstract : Field pilot tests of modified local soil/sand induced ecological restoration technology (MLS-IER) were carried out in the experimental enclosure of Meiliang Bay of Lake Taihu. The response of zoobenthos community in the experimental areas was evaluated based on the results of the survey from November 2010 to September 2011. The results revealed that the average density and biomass of mollusca in the experimental area were improved by $124 \%$ and $33.8 \%$, respectively, and the average Shannon-Wiener index and Margalef index of zoobenthos were improved by $41.1 \%$ and $18.5 \%$, respectively, compared to the control area. Canonical correspondence analysis was employed to identify the relationship between environmental factors and zoobenthos community. Chlorophyll-a, temperature, dissolved oxygen and total phosphorus concentration were found to be significant factors that influenced the zoobenthos community. This study indicated that the habitat and species diversity of the zoobenthos can be improved by the reduction of Cyano-HABs and nutrient levels, and the increase in dissolved oxygen due to the MLS-IER treatment in the enclosure.

Keywords: Modified local soil; eutrophication; zoobenthos; community structure; species diversity; Lake Taihu; Meiliang Bay

目前我国 66\% 以上的湖泊和水库处于富营养化状态,其中重富营养和超富营养的占 $22 \%$,而富营养化 所导致的蓝藻水华频发使得湖泊和水库的水质、底质条件恶化,水体生态系统和功能受到阻碍和破坏,因此 富营养化是我国现阶段亟待解决的重大水环境问题 ${ }^{[1]}$.

为实现对湖泊富营养化和蓝藻水华的长效控制,潘纲等提出并不断改进了改性当地土壤湖泊综合修复

* 国家重点基础研究发展计划 “973” 项目 (2008CB418105,2010CB933600) 资助. 2012-04-23 收稿;2012 - 05-28 收修改稿. 尚媛媛,女, 1988 年生, 硕士研究生; E-mail : shanghust@ yahoo. cn.

** 通信作者;E-mail:gpan@ rcees. ac. cn. 
技术,此技术旨在利用改性当地土壤/沙子的絮凝和吸附作用,在絮凝去除蓝藻水华的同时降低水体营养盐 含量, 然后用土壤/沙子对蓝藻絮体和沉积物进行覆盖, 抑制沉积物的再悬浮和蓝藻死亡分解导致的营养盐 再次释放,在水质和底质条件得到改善的情况下恢复水生植被,构建良好的生态系统, 提高生物多样性 ${ }^{[2-6]}$. 2006 年 8 月在太湖疗养院附近 $10 \times 10^{4} \mathrm{~m}^{2}$ 湖湾内实施了该技术, 4 个月后沉水植物得到了成功恢复, 底栖动 物多样性也有所提高 ${ }^{[2]}$, 但底栖动物群落结构和多样性对此技术的具体响应机制尚未见报道. 在水生态系 统中, 底栖动物是水生生物群落的重要组成部分, 其对环境变化的反应十分敏感, 当水体环境发生改变时, 底栖动物群落结构及多样性也将出现不同程度的响应方式 ${ }^{[7-9]}$, 如水体富营养化会导致底栖动物中软体动 物种类减少甚至消失 ${ }^{[10]}$ 、物种多样性降低 ${ }^{[9]}$, 水生态系统恢复后底栖动物多样性呈现明显提高的趋势 ${ }^{[11]}$, 因此, 研究改性当地土壤湖泊综合修复技术实施后底栖动物群落结构和多样性的响应特征和机制对于了解 该技术对水体生态系统的潜在影响及生态功能的恢复与重建具有重要意义.

本研究利用改性当地土壤/沙子湖泊综合修复技术在太湖梅梁湾围隔内实验区实施, 以实验区底栖动物 群落为研究对象, 以围隔外未采取工程处理的区域作为对照区, 通过围隔内外底栖动物群落结构和多样性的 对比研究, 探讨该技术实施后底栖动物的响应特征和机制, 为浅水湖泊的生态修复提供科学建议与技术参考.

\section{1 材料与方法}

\section{1 工程实施方式}

工程实施地点位于太湖北部梅梁湾区域的围隔, 具体位置及工程实施过程详见文献 [12]. 在围隔内实 验区设置 3 个采样点 $\left(4^{\#} \sim 6^{\#}\right)$, 同时在围隔外对照区域设置 3 个采样点 $\left(1^{\#} \sim 3^{\#}\right)$ 作为对照, 于 2010 年 11 月 至 2011 年 9 月定期采集底栖动物样品.

\section{2 底栖动物的采样与样品处理}

底栖动物样品使用 $1 / 16 \mathrm{~m}^{2}$ 改良式彼得森采泥器采集, 每个采样点采集 $1 \sim 2$ 次, 采得泥样过 $0.42 \mathrm{~mm}$ 的篎网洗涤干净后, 对剩余物进行底栖动物样品清检, 样品用 $10 \%$ 福尔马林固定. 所得样品带回实验室进行 种类鉴定和个体计数, 并用滤纸吸除底栖动物表面固定液, 置于电子天平上称重, 将结果折算成单位面积的 密度和生物量, 具体方法参照《湖泊富营养化调查规范 (第 2 版) 》 ${ }^{[13]}$.

\section{3 理化指标测定方法}

在底栖动物采样同时, 从每个采样点取 $3 \mathrm{~L}$ 水样, 每个采样点两个平行样, 测其总氮 $(\mathrm{TN})$ 、铵态氮 $\left(\mathrm{NH}_{4}^{+}-\mathrm{N}\right)$ 、硝态氮 $\left(\mathrm{NO}_{3}^{-}-\mathrm{N}\right)$ 、总磷 $(\mathrm{TP})$ 、磷酸盐 $\left(\mathrm{PO}_{4}^{3-}-\mathrm{P}\right)$ 和叶绿素 $\mathrm{a}(\mathrm{Chl} . \mathrm{a})$ 等水质指标, 其测定方法均参 考《水和废水监测分析方法 (第 4 版) 》 ${ }^{[14]}$. 底层水溶解氧 ( DO) 含量和温度 ( $\mathrm{T}$ ) 采用多参数水质测试仪 ( YSI $556 \mathrm{MPS}$, 美国) 测定, 对照区域水质指标以 $1^{\#} 、 2^{\#}$ 和 $3^{\#}$ 点的平均值表征, 实验区内水质指标以 $4^{\#} 、 5^{\#}$ 和 $6^{\#}$ 点的 平均值表征.

\section{4 数据处理}

1.4.1 优势种 由于不同种类底栖动物密度和生物量差异较大, 本研究采用相对重要性指数 $(I R I)$ 确定对照 区与实验区的优势种 ${ }^{[15]}, I R I$ 综合考虑了大型底栖动物的密度、生物量及分布状况,其计算公式为:

$$
I R I=(W+N) \cdot F
$$

式中, $W$ 为某一种类的生物量占底栖动物总生物量的百分比, $N$ 为该种类的密度占底栖动物总密度的百分 比, $F$ 为该物种出现的相对频率.

1.4.2 底栖动物多样性指数计算方法 底栖动物多样性采用 Margalef 多样性指数 ( $d$ ) 和 Shannon-Wiener 多 样性指数 $\left(H^{\prime}\right)$ 表示:

$$
\begin{gathered}
d=(S-1) / \ln N \\
H^{\prime}=-\sum\left[\left(n_{i} / N\right) \ln \left(n_{i} / N\right)\right]
\end{gathered}
$$

式中, $S$ 为种类数, $n_{i}$ 为 $i$ 种的密度 (ind. $\left./ \mathrm{m}^{2}\right), N$ 为总密度 $\left(\right.$ ind. $/ \mathrm{m}^{2}$ ); 围隔内外底栖动物的物种多样性同时用 K-优 势曲线的方法进行比较 ${ }^{[16]}$, 此方法综合了物种多样性所代表的物种丰富性与均匀性, 通过对某一特定群落内的各 个物种 (按优势度从大到小排列) 相应的累积密度百分数作图,群落的优势模式能非常直观地体现出来.

1.4 .3 统计分析 采用 $t$-检验方法检验对照区和实验区各项指标之间的差异显著性. 采用 Canoco 4.5 软件 
分析各种环境因子与底栖动物群落的关系 ${ }^{[17]}$,物种数据和环境因子均进行 $\lg (x+1)$ 转换.

\section{2 结果与讨论}

\section{1 水体主要理化指标}

2010 年 11 月至 2011 年 9 月对照区实验区主要水质理化指标的平均值见表 1 , 可见实验区各指标均优 于对照区,表明实验区水质条件已得到初步改善.

表 1 对照区和实验区水体主要理化指标平均值(2010 年 11 月一-2011 年 9 月)

Tab. 1 The average physicochemical nutrient concentration in control and experimental areas from Nov. , 2010 to Sep. , 2011

\begin{tabular}{cccccccc}
\hline & $\begin{array}{c}\mathrm{TP} / \\
(\mathrm{mg} / \mathrm{L})\end{array}$ & $\begin{array}{c}\mathrm{PO}_{4}^{3-}-\mathrm{P} / \\
(\mathrm{mg} / \mathrm{L})\end{array}$ & $\begin{array}{c}\mathrm{TN} / \\
(\mathrm{mg} / \mathrm{L})\end{array}$ & $\begin{array}{c}\mathrm{NO}_{3}^{-}-\mathrm{N} / \\
(\mathrm{mg} / \mathrm{L})\end{array}$ & $\begin{array}{c}\mathrm{NH}_{4}^{+}-\mathrm{N} / \\
(\mathrm{mg} / \mathrm{L})\end{array}$ & $\begin{array}{c}\mathrm{Chl} . \mathrm{a} / \\
(\mu \mathrm{g} / \mathrm{L})\end{array}$ & $\begin{array}{c}\mathrm{DO} / \\
(\mathrm{mg} / \mathrm{L})\end{array}$ \\
\hline 对照区 & 0.32 & 0.045 & 3.64 & 2.08 & 0.61 & 52.77 & 9.10 \\
实验区 & 0.26 & 0.018 & 2.19 & 1.07 & 0.29 & 32.29 & 9.63 \\
\hline
\end{tabular}

\section{2 底栖动物群落结构}

2.2 .1 底栖动物的组成分布 由于 $1^{\#} \sim 3^{\#}$ 及 $4^{\#} \sim 6^{\#}$ 处理内底栖动物的密度和生物量均无显著性差异, 在具 体分析时分别将对照区和实验区的样点取平均值进行比较研究. 经鉴定, 对照区与实验区共发现底栖动物 14 种, 其中软体动物 2 种, 水栖塞毛类 4 种, 水生昆虫 7 种, 其他动物 1 种 (表 2 ). 从群落的种类组成看, 在监 测期间对照区与实验区底栖动物种类数量均较少且无明显差别, 底栖动物群落主要由软体动物、水栖寡毛 类和水生昆虫组成. 对照区内铜锈环棱螺、霍甫水丝蚓和长足摇蚊成为优势种, 实验区内河蚬、铜锈环棱螺、 霍甫水丝蚓和红裸须摇蚊成为优势种, 其中围隔内外霍甫水丝蚓的 IRI 值均处于第一位, 且与其他物种的 $I R I$ 值相差较大, 可见霍甫水丝蚓在围隔内外均处于绝对优势地位 (表 2). 霍甫水丝蚓、长足摇蚊和红裸须 摇蚊常在湖泊水体严重富营养化时大量出现,这主要是由于其对有机物大量分解造成的低氧缺氧环境的耐 受力很强, 因而得以生存 ${ }^{[9,18-20]}$.

围隔外对照区底栖动物的平均密度为 $280.9 \mathrm{ind} . / \mathrm{m}^{2}$, 其中葟毛类平均密度最高 $\left(199.1 \mathrm{ind} . / \mathrm{m}^{2}\right.$, 占总密度的 $70.89 \%$ ), 其次是水生昆虫和软体动物,平均密度分别为 72.9 和 $5.3 \mathrm{ind} . / \mathrm{m}^{2}$, 分别占总密度的 $25.95 \%$ 和 $1.90 \%$; 实验区底栖动物平均密度为 $179.9 \mathrm{ind} . / \mathrm{m}^{2}$, 其中寡毛类、水生昆虫和软体动物的平均密度分别为 $113.8 、 53.3$ 和 $12.1 \mathrm{ind} . / \mathrm{m}^{2}$, 分别占总密度的 $63.26 \% 、 29.65 \%$ 和 $6.75 \%$ (表 2). 比较可知, 实验区底栖动物平均密度相比对照区 较小,这可能是由于当地土壤/沙子覆盖对底栖动物的摄食或生活方式有一定的影响.

实验区底栖动物平均生物量为 $18.99 \mathrm{~g} / \mathrm{m}^{2}$, 相比对照区的 $14.21 \mathrm{~g} / \mathrm{m}^{2}$ 较大 (表 $2, P<0.05$ ). 围隔内外 软体动物生物量均占总生物量的 $90 \%$ 以上, 其在实验区的平均生物量为 $17.91 \mathrm{~g} / \mathrm{m}^{2}$, 高于对照区的 $13.38 \mathrm{~g} / \mathrm{m}^{2}$ (表 $2, P<0.05$ ), 且以河蚬对此贡献较大. 一般认为, 河蚬和铜锈环棱螺等软体动物耐污能力相 对寡毛类较弱,在富营养化严重、底泥厌氧的区域存量较少甚至消失 ${ }^{[10,21-22]}$. 蔡永久等 ${ }^{[22]}$ 发现河蚬适于生长 在粒径范围较广, 含氧量较高的砂质底质中. 实验区底质经过覆沙处理转变为粒径范围较广的粗砂底质, 且 溶解氧含量有所提高, 水质条件较对照区有所好转 (表 1), 为河蚬的生长繁殖提供了有利的生境条件.

2.2.2 底栖动物的密度及生物量的变化 对照区底栖动物密度在 2 月最高, 9 月最低, 实验区底栖动物密度 的变化趋势与对照区较为一致 (图 1a). 对照区底栖动物的生物量在 6 月达到最高点,最低点出现在 9 月,而 实验区底栖动物的生物量在 8 月达到最高点,最低点出现在 5 月 (图 $1 \mathrm{~b}$ ).

实验区和对照区底栖动物的密度随季节变动明显, 现存量在夏、秋季较低, 而在冬、春季较高, 这与底栖动 物的生殖季节及发育越冬过程都有较密切的关系. 有研究表明, 底栖动物特别是水生昆虫的密度和生物量在 水温高时较低,这与它们一般以幼虫过冬、次年逐步羽化离开水体有关 ${ }^{[23]}$. 同时,相比对照区, 监测期间实验区软 体动物的生物量在 3 月和 6 月较低 (图 $1 \mathrm{~b}$ ). 实验区底栖动物的生物量在冬、春季较低,在夏、秋季较高, 而围隔外 对照区底栖动物的生物量在春、夏季较高,在秋、冬季较低. 研究显示,软体动物 (如铜锈环棱螺和河蚬)一般在春季 性成熟,因而其生物量在冬、春季较低,在夏、秋季较高 ${ }^{[24-25]}$. 对照区内软体动物生物量的变化趋势与此结果不一致 可能是由夏、秋季对照区水体营养水平较高且有蓝藻水华暴发 ${ }^{[12]}$,软体动物的耐污能力较弱造成的. 
表 2 对照区与实验区底栖动物的平均密度、生物量与 $I R I(2010$ 年 11 月- 2011 年 9 月)

Tab. 2 The mean density, biomass and IRI of zoobenthos in control and experimental areas from Nov. , 2010 to Sep. , 2011

\begin{tabular}{|c|c|c|c|c|c|c|}
\hline \multirow[b]{2}{*}{ 底栖动物 } & \multicolumn{3}{|c|}{ 对照区 } & \multicolumn{3}{|c|}{ 实验区 } \\
\hline & $\begin{array}{c}\text { 密度/ } \\
\left(\text { ind. } / \mathrm{m}^{2} \text { ) }\right.\end{array}$ & $\begin{array}{l}\text { 生物量/ } \\
\left(\mathrm{g} / \mathrm{m}^{2}\right)\end{array}$ & IRI & $\begin{array}{c}\text { 密度/ } \\
\left(\text { ind. } / \mathrm{m}^{2}\right)\end{array}$ & $\begin{array}{l}\text { 生物量/ } \\
\left(\mathrm{g} / \mathrm{m}^{2}\right)\end{array}$ & IRI \\
\hline \multicolumn{7}{|l|}{ 软体动物 (Mollusca) } \\
\hline 河蚬 (Corbicula fluminea) & 1.8 & 0.05 & 0.006 & 6.8 & 9.58 & 2.055 \\
\hline 铜锈环棱螺 (Bellamya aeruginosa) & 3.6 & 13.33 & 1.203 & 5.3 & 8.33 & 1.388 \\
\hline \multicolumn{7}{|l|}{ 水栖寡毛类( Oligochaeta) } \\
\hline 霍甫水丝蚓( Limnodrilus hoffmeisteri) & 188.4 & 0.48 & 47.282 & 102.8 & 0.18 & 33.210 \\
\hline 管水蚓(Aulodrilus sp. ) & 3.6 & 0 & 0.016 & 1.2 & 0.03 & 0.005 \\
\hline 苏氏尾鳃蚓 (Branchiura sowerbyi) & 3.6 & 0.02 & 0.018 & 9.8 & 0.36 & 0.398 \\
\hline 尾盘虫 ( Dero sp. ) & 3.6 & 0 & 0.016 & 0 & 0 & 0 \\
\hline \multicolumn{7}{|l|}{ 水生昆虫 ( Insecta) } \\
\hline 半折摇蚊 (Chironomus semireductus) & 0 & 0 & 0 & 0.6 & 0.01 & 0.001 \\
\hline 长足摇蚊 ( Tanypus sp.) & 58.7 & 0.23 & 4.706 & 8.6 & 0.07 & 0.245 \\
\hline 雕翅摇蚊 (Glyptotendipes sp. ) & 0 & 0 & 0 & 10.7 & 0.04 & 0.363 \\
\hline 多足摇蚊 (Polypedilum sp.) & 1.8 & 0 & 0.004 & 1.5 & 0 & 0.007 \\
\hline 红裸须摇蚊 (Propsilocerus akamusi) & 7.1 & 0.09 & 0.080 & 20.1 & 0.39 & 1.484 \\
\hline 小摇蚊 ( Microchironomus sp. ) & 3.6 & 0 & 0.016 & 1.8 & 0 & 0.010 \\
\hline 隐摇蚊 (Cryptochironomus sp.) & 1.8 & 0 & 0.004 & 10.1 & 0.02 & 0.320 \\
\hline \multicolumn{7}{|l|}{ 其他动物 (others) } \\
\hline 钩虾 ( Gammarus sp.) & 3.6 & 0 & 0.016 & 0.6 & 0 & 0.001 \\
\hline 合计 & 280.9 & 14.21 & & 179.9 & 18.99 & \\
\hline
\end{tabular}

\section{$\square$ 软体动物 日寡毛类 口摇蚊类 口其他类}

a

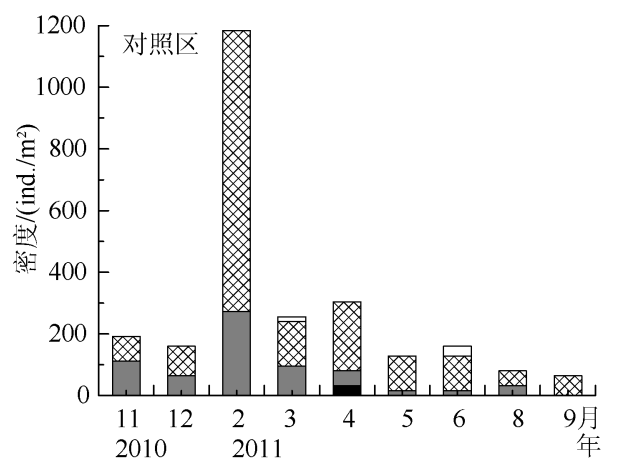

b

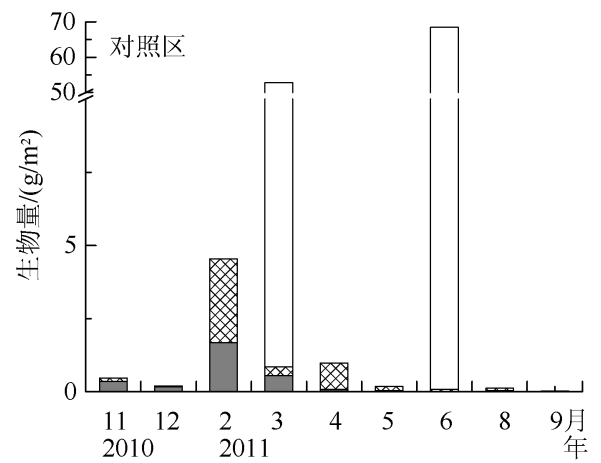

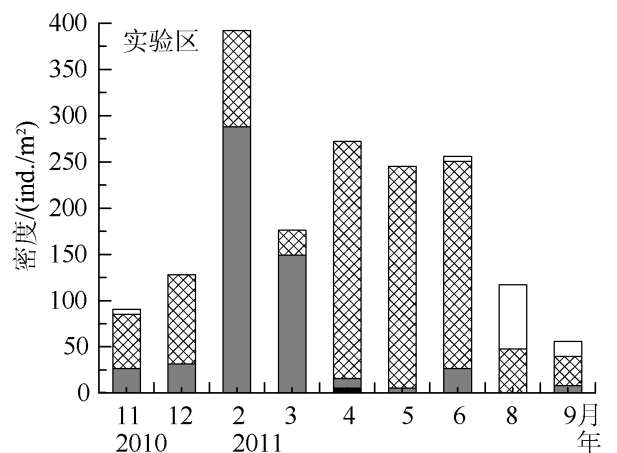

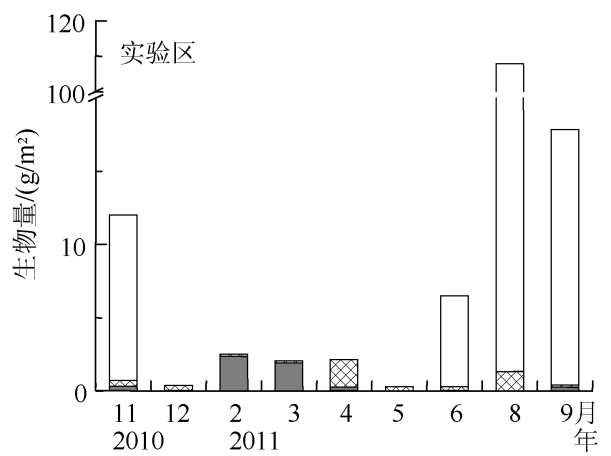

图 1 对照区和实验区底栖动物密度 (a) 和生物量 (b) 的时间变化 (2010 年 11 月-2011 年 9 月)

Fig. 1 The temporal variations of density (a) and biomass (b) of zoobenthos in control and experimental areas from Nov. , 2010 to Sep. , 2011 


\section{3 底栖动物的多样性}

Shannon-Wiener 指数被认为能相对较为客观地评价多样性和水质受污染状况,一般认为此指数大于 3 为清洁水体, 在 $2 \sim 3$ 之间为轻度污染, 在 $1 \sim 2$ 之间为中度污染, 小于 1 为重污染, 0 为严重污染 ${ }^{[11]}$. 对照区、 实验区底栖动物 $H^{\prime}$ 分别为 $1.12 、 1.58, d$ 分别为 $1.95 、 2.31$, 可见围隔内外区域水质污染情况仍较为严重,但 相比对照区, 实验区 $H^{\prime}$ 和 $d$ 均有所提高 $(P<0.05)$.

比较围隔内外底栖动物 $\mathrm{K}-$ 优势曲线可知 (图 2), 实验 区底栖动物物种数虽无明显增多, 但实验区 $\mathrm{K}$-优势曲线上 的所有点都位于对照区之下,说明其物种分布更趋均匀,即 多样性有所提高. 龚志军等针对武汉东湖不同富营养水平 湖区的底栖动物多样性研究 ${ }^{[9]}$ 表明, 富营养化程度较高的 区域底栖动物多样性降低. 段学花等 ${ }^{[26]}$ 和蔡永久等 ${ }^{[27]}$ 研 究发现底质类型对底栖动物多样性也有显著影响, 颗粒粒 径大、孔隙率大的砂质底质物种多样性更高. 国内外许多关 于底栖动物多样性与生境关系的研究 ${ }^{[28-29]}$ 认为, 生境的复 杂性是决定底栖动物多样性的关键因子, 而水生植物能为 底栖动物提供更加多样的栖息、繁殖场所,增加更多可供底 栖动物生存的生境空间. 间云君等 ${ }^{\left[{ }^{[} 0\right]}$ 在比较研究草型湖泊 与藻型湖泊的群落结构时也发现草型湖泊中底栖动物多样 性明显高于藻型湖泊. 改性当地土壤技术实施后, 实验区 水质条件得到改善 (表 1 ), 底质经过覆沙处理转变为粒径 范围较广的粗砂底质, 菹草和马来眼子菜等大型沉水植物 得到一定程度的恢复, 形成的更加多样的小生境为底栖动 物提供了生存空间和庇护场所, 从而增加了某些种类的生 存机会, 提高了实验区底栖动物的物种多样性.

\section{4 底栖动物群落与水体理化指标的关系}

选用 7 种水质理化指标 $\left(\mathrm{DO} 、 \mathrm{~T} 、 \mathrm{TN} 、 \mathrm{NH}_{4}^{+}-\mathrm{N} 、 \mathrm{TP} 、 \mathrm{PO}_{4}^{3-}-\mathrm{P}\right.$ 和 Chl. a) 与底栖动物群落进行典范对应分析, 排序结果如 图 3 所示. 前两个排序轴的特征值分别为 0.203 和 0.112 , 分别解释了底栖动物群落结构变异的 $6.6 \%$ 和 $3.6 \%$, 解释 的物种一环境变异百分比分别为 $42.2 \%$ 和 $23.4 \%$,参与分 析的这 7 种理化指标能解释底栖动物种群密度波动的 $15.5 \%$, 这说明还有其它环境因素, 如底质情况、生境的异 质性等, 影响着底栖动物的群落结构. 通过 Monte Carlo 测 试, Chl. a、T、DO 和 TP 是对底栖动物群落结构影响较为显 著的因子 $(P<0.05)$. 从排序图中还可以看出, 霍甫水丝蚓 与 Chl. a 和 TP 呈正相关, 与 DO 呈负相关; 红裸须摇蚊与 DO 呈正相关, 与 Chl. a 和 TP 呈负相关 (图 3).

Chl. a 和 TP 反映水体富营养化程度和蓝藻水华暴发 的程度, 龚志军等 ${ }^{[9]}$ 发现东湖不同湖区霍甫水丝蚓的密度 分布与水体营养水平呈明显正相关的趋势, 本研究的典范

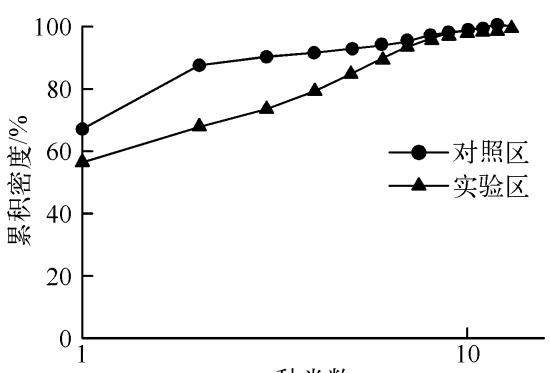

种类数

图 2 对照区与实验区底栖动物的 $\mathrm{K}-$ 优势曲线

Fig. 2 K-dominant curves of zoobenthos in control and experimental areas

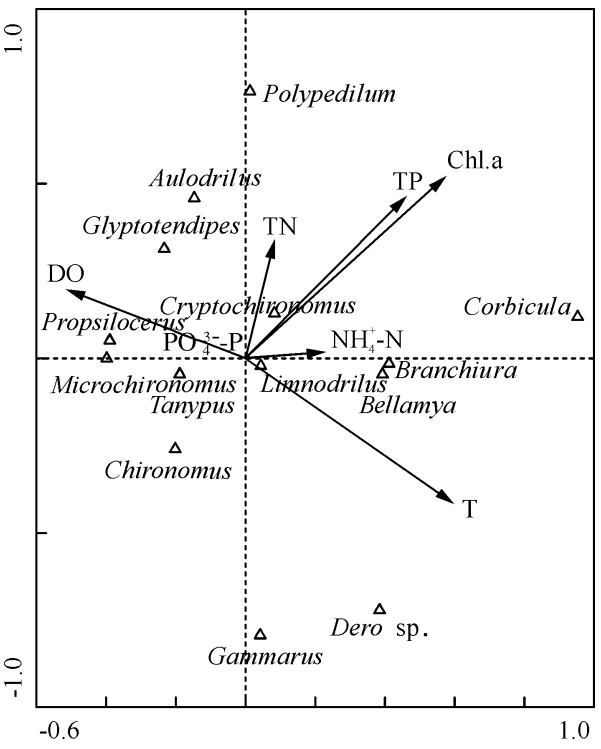

图 3 采样点底栖动物与环境因子的 $\mathrm{CCA}$ 二维关系排序图

Fig. 3 CCA two-dimensional ordination diagram of zoobenthos-environmental factors in the sampling sites 对应分析结果与其相符. 而红裸须摇蚊表现出的与营养水平和蓝藻水华暴发程度的负相关可能类似龚志军 等研究中出现的单峰分布的情况 ${ }^{[9]}$. 由于监测期间围隔外对照区水体营养水平较高且暴发了蓝藻水华 ${ }^{[12]}$, 红裸须摇蚊与 DO 呈正相关、与 Chl. a 和 TP 呈负相关,表明红裸须摇蚊对蓝藻水华和水体富营养化水平的 耐受性较霍甫水丝蚓差. 底栖动物群落中绝对优势种霍甫水丝蚓与溶解氧呈显著负相关关系, 这与程睖等对 
苏州河的研究结果 ${ }^{[31]}$ 类似, 且其与 Chl. a 和 TP 的正相关关系表明, 霍甫水丝蚂是一种很好的富营养化污染 指示生物 ${ }^{[9]}$. 结合围隔内实验区 K-优势曲线上的所有点均位于对照区之下的情况 (图 2), 本研究表明改性 当地土壤技术可以通过改善湖泊富营养化和溶解氧环境低下的状况改善底栖动物群落中霍甫水丝蚓占绝 对优势的情况, 提高底栖动物物种的多样性, 改善底栖生态系统.

本研究中围隔内实验区与围隔外对照区仍存在空间上的不一致性, 围隔外可能会受到较大的外界干 扰, 因此还需要在科学的全湖实验体系中进一步研究改性当地土壤技术实施后水体生态系统的长期响应.

\section{3 结论}

为研究底栖动物群落对改性土壤技术的响应, 在太湖梅梁湾围隔内实验区实施该技术后, 于 2010 年 11 月到 2011 年 9 月进行定期监测, 实验结果表明:1) 监测期间实验区底栖动物平均密度相比对照区较小, 但 种类数和优势种差别不大, 说明改性当地土壤技术的实施并未威胁底栖动物的生存, 对底栖动物具有较好 的生态安全性. 2) 工程实施后, 水体营养盐和叶绿素 a 含量降低, 底泥表层溶解氧含量增加, 菹草和马来眼 子菜等沉水植物得到一定程度的恢复, 耐污能力较弱的软体动物平均密度和生物量相比对照区均有所增 加, 且底栖动物多样性也有所提高. 3) 结合本系列首篇文章讨论可知, 改性当地土壤技术可通过絮凝除藻快 速改善水体水质环境, 通过沙土覆盖藻絮体实现对水体营养盐水平的长效控制, 同时将底质转变为粒径范 围较广的粗砂底质, 增加底泥表层溶解氧含量, 促进大型沉水植物的恢复, 从而在底质中形成更加多样的小 生境, 降低霍甫水丝蚓在底栖动物群落中的绝对优势情况, 增大其他物种的生存机会, 提高底栖动物的物种 多样性.

\section{4 参考文献}

[ 1 ] 黄渏平. 太湖水环境及其污染控制. 北京:科学出版社, 2001:1-298.

[ 2 ] Pan G, Yang B, Wang D et al. In-lake algal bloom removal and submerged vegetation restoration using modified local soils. Ecological Engineering, 2011, 37(2):302-308.

[ 3 ] Pan G, Zhang MM, Chen H et al. Removal of cyanobacterial blooms in Taihu Lake using local soils. I. Equilibrium and kinetic screening on the flocculation of Microcystis aeruginosa using commercially available clays and minerals. Environmental Pollution, 2006, 141 (2) :195-200.

[ 4 ] Zou H, Pan G, Chen H et al. Removal of cyanobacterial blooms in Taihu Lake using local soils. II. Effective removal of Microcystis aeruginosa using local soils and sediments modified by chitosan. Environmental Pollution, 2006 , 141 (2):201 205 .

[ 5 ] Pan G, Zou H, Chen H et al. Removal of harmful cyanobacterial blooms in Taihu Lake using local soils. III. Factors affecting the removal efficiency and an in situ field experiment using chitosan-modified local soils. Environmental Pollution, 2006,141 (2):206-212.

[ 6 ] Pan G, Chen J, Anderson DM. Modified local sands for the mitigation of harmful algal blooms. Harmful Algae, 2011 , 10 (4) :381-387.

[7] 刘保元, 邱东茹, 吴振斌. 富营养浅湖水生植被重建对底栖动物的影响. 应用与环境生物学报, 1997, 3 (4): $323-327$.

[ 8 ] Norkko A, Bonsdorff E. Rapid zoobenthic community responses to accumulations of drifting algae. Marine Ecology Progress Series, 1996, 131:143-157.

[9] 龙志军, 谢 平, 唐汇涓等. 水体富营养化对大型底栖动物群落结构及多样性的影响. 水生生物学报, 2001, 25 (3): 210-216.

[10] 熊金林, 梅兴国, 胡传林. 不同污染程度湖泊底栖动物群落结构及多样性比较. 湖泊科学, 2003,15(2): 160-168.

[11] 孔繁翔. 环境生物学. 北京: 高等教育出版社, 2000 .

[12] 潘 纲,代立春, 李 梁等. 改性当地土壤技术修复富营养化水体综合效果研究: I. 水质改善的应急与长期效果 与机制. 湖泊科学, $2012,24(6): 801-810$.

[13] 金相灿, 屠清瑛. 湖泊富营养化调查规范:第 2 版. 北京: 中国环境科学出版社, 1990.

[14] 国家环境保护总局《水和废水监测分析方法》编委会. 水和废水监测分析方法:第 4 版. 北京: 中国环境科学出版 
社,2002.

［15］韩 洁,张志南,于子山. 渤海中、南部大型底栖动物的群落结构. 生态学报,2004,24(3):531-537.

[16] Platt HM, Shaw KM, Lambshead PJD. Nematode species abundance patterns and their use in the detection of environmental perturbations. Hydrobiologia , 1984, 118 (1) :59-66.

[17] Terbraak CJF, Verdonschot PFM. Canonical correspondence analysis and related multivariate methods in aquatic ecology. Aquat Sci, 1995, 57(3):255-289.

[18 ] Iwakuma T, Yasuno M. Fate of the univoltine chironomid, tokunagayusurika-akamusi (diptera, chironomidae), at emergence in Lake Kasumigaura, Japan. Archiv fiur Hydrobiologie, 1983, 99(1) :37-59.

[19] Devai G, Moldovan J. An attempt to trace eutrophication in a shallow lake (Balaton, Hungary) using chironomids. Hydrobiologia, 1983, 103(1):169-175.

[20 ] Brinkhurst RO. The benthos of lakes. New Jersey: Blackbum Press, 1974.

[21］刘敬泽. 监测水环境变化的大无脊椎动物. 生物学通报, 1999,34(1):36.

[22] 蔡永久,龚志军,秦伯强. 太湖软体动物现存量及空间分布格局(2006-2007 年). 湖泊科学, 2009,21 (5):713-719.

[23] Kroncke I, Dippner JW, Heyen H et al. Long-term changes in macrofaunal communities off Norderney (East Frisia, Germany) in relation to climate variability. Marine Ecology-Progress Series, 1998, 167 : 25-36.

[24] 龚志军,李艳玲, 谢 平. 武汉东湖铜锈环棱螺的种群动态及次级生产力. 湖泊科学, 2009,21(3):401-407.

[25] 蔡 炜,蔡永久,龚志军等.太湖河蚬时空格局. 湖泊科学,2010,22(5):714-722.

[26] 段学花,王兆印,田世民. 河床底质对大型底栖动物多样性影响的野外试验. 清华大学学报: 自然科学版,2007,47 (9) :1553-1556.

[27］蔡永久,龚志军,秦伯强. 太湖大型底栖动物群落结构及多样性. 生物多样性,2010,18(1):50-59.

[28] Tolonen KT, Hamalainen H, Holopainen IJ et al. Influences of habitat type and environmental variables on littoral macroinvertebrate communities in a large lake system. Archiv für Hydrobiologie, 2001, 152 (1) : 39-67.

[29] Shostell JM, Williams BS. Habitat complexity as a determinate of benthic macroinvertebrate community structure in cypress tree reservoirs. Hydrobiologia, 2007, 575 :389-399.

[30］间云君,李晓宇, 梁彦龄. 草型湖泊和藻型湖泊中大型底栖动物群落结构的比较. 湖泊科学, 2005,17(2):176-182.

[31］程 䂀, 李小平, 陈小华. 苏州河水质和底栖动物群落 $1996 \sim 2006$ 年的时空变化. 生态学报, 2009, 29 (6) : $3278-3287$. 